\title{
TRANSFORMAÇÕES NA LINGUAGEM DO TEATRO DE ANIMAÇÃO: a criação do espetáculo teatral ${ }^{1,2}$
}

\author{
Valmor Beltrame ${ }^{3}$
}

Resumo: O teatro de animação no Brasil conquistou, a partir dos anos de 1970, um nível de maturidade diferenciando-o das práticas predominantes registradas nos anos anteriores. Certas evidências possibilitam afirmar que essa arte, antes homogênea, se torna híbrida. A pesquisa que atualmente realizo intitulada "Teatro de bonecos: transformações na poética da linguagem", objetiva analisar as principais mudanças ocorridas nessa arte no Brasil. Neste texto discuto a existência de diferenciados modos de criação do espetáculo teatral, um dos eixos de análise da pesquisa.

PALAVRAS-CHAVE: Teatro de Bonecos; Heterogeneidade no Teatro de Bonecos; Linguagem Cênica; Transformações no Teatro de Animação.

Destacar as principais transformações ocorridas no Teatro de Animação nas últimas décadas constitui um desafio importante para compreender a diversidade de práticas que ocorrem atualmente neste campo artístico. $\mathrm{O}$ teatro de animação brasileiro sofreu visíveis transformações nos últimos anos. Deixou de ser arte destinada exclusivamente para crianças e superou a visão de cronistas, historiadores e viajantes pelo interior do País que, no século XVIII, viam o teatro de bonecos popular como "uma ingênua diversão do povo" (BORBA FILHO, 1987, p.56).

As ações em busca do reconhecimento e da valorização desse teatro ganharam visibilidade a partir da década de 1970 e se devem ao trabalho de grupos de diferentes regiões do Brasil e seus espetáculos com apurada elaboração técnica e artística, que contribuíram para superar visões estereotipadas sobre sua linguagem. Ajudaram nesse processo de mudança, as oportunidades de reflexões criadas em eventos promovidos pela ABTB - Associação Brasileira de Teatro de Bonecos, nos festivais organizados em diversas regiões; as atividades relacionadas à formação, como a inclusão de disciplinas específicas nas universidades; e as iniciativas na publicação de estudos e pesquisas acadêmicas sobre teatro de animação. Essas transformações ocorrem de modo bastante visível nas atividades artísticas de grupos situados em diversos centros urbanos, ao mesmo tempo em que muitas manifestações do teatro de bonecos popular e tradicional são praticadas no interior do país.

1 Trabalho oriundo da Pesquisa "Teatro de Bonecos: transformações na poética da linguagem".

2 Parte deste texto (com cerca de 1800 palavras) foi publicada em 2007 no livro Vida de Boneco. Curitiba: ImagemSul.

3 Professor Doutor, Orientador da Pesquisa, Docente CEART/UDESC. 
O Brasil é um dos poucos países onde ainda se mantém vivo um teatro de bonecos praticado por artistas do povo. Em alguns estados do nordeste brasileiro, mais especialmente em Pernambuco, existe uma forma de teatro de títeres conhecida como mamulengo. Os mamulengueiros são homens simples, pobres, muitos deles analfabetos, no entanto, são conhecidos como "Mestres". Os artistas que fazem essa "brincadeira" criam, detêm e perpetuam os saberes de sua arte (SANTOS, 2007 p.33).

A continuidade e preservação do mamulengo estão intimamente ligadas à transmissão oral e, sobretudo, à observação da prática, à forma de representá-lo. O que é transmitido aos aprendizes do mamulengo pode ser compreendido como técnicas, ou "estruturas materiais e imaginárias" ou ainda como "técnicas codificadas de longa duração.” Para Eugenio Barba (1995, p.19), essas práticas artísticas vão construindo um acervo de procedimentos e concepções incorporados por mestres do ofício, e constituem um "conjunto de bons conselhos" aos quais o aprendiz recorre e faz uso.

O mamulengo, assim como outras formas de manifestação do teatro popular brasileiro, tais como o Teatro de João Redondo, Cassemiro Coco, Babau, e danças dramáticas como o Bumba-meu-Boi, Cavalo Marinho e Boi-de-Mamão, apenas para citar algumas expressões, continuam estimulando os processos criativos de grupos de teatro em diversas regiões do país.

Nas áreas urbanas do país é possível perceber que hoje a criação de espetáculos de teatro de animação incorpora inúmeros recursos, linguagens, procedimentos que o tornam heterogêneo e híbrido. A sua proximidade com outras linguagens artísticas, incluindo a dança, mímica, circo, espetáculo multimídia, entre outros, torna essa arte reconhecidamente mais contemporânea, caminhando numa direção que a aproxima de outros campos das artes cênicas, visuais, fazendo com que as fronteiras entre as linguagens fiquem cada vez mais difusas. E isso se deve ao uso de variados meios de expressão, ao abandono do boneco do tipo antropomorfo, à ruptura com o palquinho tradicional do teatro de bonecos e à presença visível do ator-animador na cena.

Atualmente já existem diversos conceitos que colaboram para aprofundar este tema. Recente estudo de Jorge Dubatti (2007, p.178) enumera expressões que remetem a concepções diferenciadas para refletir sobre as práticas situadas em fronteiras borradas nos diversos campos artísticos. Destacam-se terminologias como: liminalidade, hibridação, contaminação, fronteiras, complexidade, transversalidade, mestiçagem, heterogeneidade. 
No atual estágio dessa pesquisa, que pretende compreender as principais transformações efetuadas na criação de espetáculos de teatro de animação é fundamental a idéia de hibridação apresentada por Nestor Garcia Canclini: "Entendo por hibridação processos sócio-culturais nos quais estruturas ou práticas discretas, que existiam de forma separada, se combinam para gerar novas estruturas, objetos e práticas" (CANCLINI, 2003 p.XIX). Ou seja, o teatro de bonecos tradicional, ao associar-se com outras linguagens artísticas abandona sua característica homogênea e cria novas estruturas nas quais se evidencia a pluralidade de práticas criativas que se diferenciam do modo como historicamente era praticado. Ao mesmo tempo a hibridação vivida nessa arte nos últimos anos inclui a mescla de elementos de outras culturas. A idéia de estrutura aqui é compreendida como ato criador que evidencia a poética do grupo ou do artista.

É importante frisar que a inclusão de expressões de outros campos artísticos na encenação não caracteriza a hibridação que atualmente se discute. $\mathrm{O}$ ato de agregar ao espetáculo outras linguagens pode ter função meramente ilustrativa, não caracterizando o que se compreende por heterogeneidade. O desafio é miscigenar dando unidade, organicidade, fazendo com que cada elemento agregado, seja visual ou sonoro, também construa a teatralidade do espetáculo.

Essas mudanças também são visíveis nas nomenclaturas utilizadas para denominar essa arte. Até os anos de 1970 era mais conhecida como Teatro de Títeres, Teatro de Fantoches ou Teatro de Marionetes. Em seguida, passou a ser comumente denominada de Teatro de Bonecos. Posteriormente, Teatro de Formas Animadas, e mais recentemente, Teatro de Animação. O uso de cada uma dessas expressões revela distintos modos de conceber essa arte e principalmente a complexidade que hoje se reveste. No entanto, em cada uma dessas nomenclaturas que indicam diferentes concepções sempre haverá o que mais caracteriza esse teatro: a presença da forma animada pelo bonequeiro, titeriteiro, ou ator-animador.

Aí reside o maior desafio desse artista: animar a forma inanimada, transpor suas emoções ao objeto, fazer a transfiguração do objeto aparentemente inerte em personagem. O complexo trabalho do ator-animador consiste em estabelecer a comunicação com o público mostrando um personagem que não se apresenta no seu corpo, mas num objeto. A relação com a platéia é mediada pelo objeto animado. Recente estudo publicado na Revista Móin-Móin n5 afirma que: 
[...] destacam-se ainda outras transformações importantes na prática do Teatro de Animação contemporâneo, tais como: a pluralidade de linguagens e a fragmentação da narrativa como procedimentos recorrentes nessa prática teatral, o que confirma a predominância de linguagens híbridas e miscigenadas; a combinação de variados meios de expressão num mesmo espetáculo utilizando tanto recursos do vasto campo do Teatro de Formas Animadas quanto de outras linguagens artísticas; a utilização de formas e de objetos extraídos do cotidiano que se transformam em personagens ou "figuras" animadas na cena; a presença do ator-animador que co-divide com o boneco a configuração da personagem; e a intertextualidade como prática que amplia a concepção de dramaturgia (BELTRAME, 2007, p.09).

É possível acrescentar ainda, rupturas com os códigos e registros que caracterizam o teatro de bonecos tradicional, tais como: a eliminação da empanada ou palquinho que esconde o ator-animador; a recorrência a bonecos do tipo antropomorfo; a obediência ao uso de uma única linguagem, impedindo o uso de bonecos com variadas formas de confecção e técnicas de animação. Refletindo sobre novas perspectivas dessa linguagem, Felisberto Costa afirma que:

Partindo-se da perspectiva da atuação com objetos, descortina-se um universo artístico em constante expansão, em que o objeto pode ser animado, manipulado, manuseado, acionado, expressar-se por si, não mostrando nada mais do que ele mesmo, entre tantas outras invenções. Os avanços experimentados apontam, num futuro próximo, para novas possibilidades do Teatro de Animação, no que diz respeito ao ato performativo com objetos (COSTA, 2008, p.10).

A diversidade de maneiras de utilização de objetos e bonecos assim como as formas de criação do espetáculo teatral hoje também são bastante diversificadas, mas é interessante destacar a existência de pelo menos três eixos norteadores desse processo. Ao evidenciar três facetas da criação de espetáculos de teatro de animação contemporâneo, não significa dizer que essas sejam as formas mais recorrentes. Essas facetas são importantes porque revelam a existência de trajetórias distintas no modo de criar e comprovam a maturidade e desenvolvimento dessa arte. São elas:

a) a recriação do regional/popular - A apropriação de elementos da cultura regional/popular na montagem de espetáculos de teatro de bonecos não é fenômeno recente. Desde os anos de 1960 e 1970 essa prática é muito comum. Alguns elementos que nortearam a criação de espetáculos naquela época ainda hoje são utilizados, como por exemplo, a recriação de lendas, folguedos e falares do povo. Desde então, os espetáculos que se mantêm vivos e provocam alguma repercussão são os que, em vez de transpor expressões populares para o palco, as recriam, reinventam, incluindo elementos que tornam o espetáculo universal, ampliando as fronteiras do seu sentido e 
compreensão regional. Ao se apropriar do teatro de bonecos tradicional e incluir novos elementos tanto no processo de confecção dos bonecos, quanto na estruturação do trabalho cênico, estes espetáculos transitam entre o que na linguagem do senso comum pode se configurar como o "culto e o popular".

O novo dessa prática também reside no fato de contribuir para o fortalecimento de "identidades", ultrapassando os limites do que se poderia configurar como espetáculo baseado na cultura local, como algo pitoresco ou exótico.

Personagens como Tiridá, Benedito, Simão, entre outros, vivos na nossa rica tradição do mamulengo e presentes nos espetáculos de diversos grupos, colaboram na construção de identidades, uma idéia de pertencimento que vai se esboçando e se realizando na conduta dos personagens e na poética dos espetáculos. A idéia de "diferença" que permeia a forma de ser desses personagens e o universo no qual se situam são vistos e tratados como elementos que constroem um jeito de ser, outro modo de ver e estar no mundo. O modo de criar esses espetáculos evidencia que não existe uma cultura, mas muitas culturas. E assim contribuem para a compreensão de existência de um pluralismo cultural.

Um dado novo presente nesse modo de criar espetáculos também aparece no comportamento de diretores e dramaturgos que se comportam como "reaproveitadores e redefinidores de expressões". Ao se apropriarem de elementos dessa cultura para a encenação, demonstram que elementos da cultura local podem ser universais, porque tratam dos problemas mais fundamentais do ser humano.

Os trabalhos dos Grupos Mamulengo Só-Riso, da cidade de Olinda - PE, sob a direção de Fernando Augusto Gonçalves Santos; Mamulengo Presepada, de Brasília DF, dirigido por Chico Simões; Valdecke de Garanhuns, atualmente residindo em São Paulo - SP; e o trabalho de Augusto Bonequeiro, em Fortaleza - CE, exemplificam, cada um a seu modo e com suas peculiaridades, essa tendência de criação de espetáculos pautado na recriação do regional/popular.

b) a dramaturgia desconstruída ou a cena fragmentada - Esse procedimento nasce do desejo de rompimento com as tradicionais formas de criação do texto ou enredo. Já não interessa a dramaturgia tradicional, a peça "bem feita", aquela com início, meio e fim. Nesse tipo de proposta, interessa oferecer poucas informações, estimulando o espectador a fazer seu quebra-cabeças, cujas peças são dadas aos poucos, possibilitando a ele ir formando seu quadro, compondo com seu imaginário. A idéia de que o 
espectador pode, ele mesmo, a partir de estímulos apresentados, criar uma narrativa própria conta principalmente com o seu envolvimento emocional no espetáculo.

O trabalho da construção dramatúrgica consiste em percorrer outro caminho, diferente, tendo um tema central como princípio norteador. Nega-se o texto racionalista, a idéia de que o conhecimento e a experiência significativa só são possíveis através do pensamento lógico, do discurso e do intelecto. Por isso, outra característica dessa proposta é a economia de palavras, ou a eliminação do texto verbal, o texto pronunciado.

A eliminação de palavras, o dizer com ações e gestos, a ação destituída de fala, exige trabalhar com o princípio que conta com a clareza do gesto e do movimento. Com isso, o tempo dos ensaios é ampliado por que ali se exige não só o tempo de aperfeiçoamento da cena, mas principalmente, de construção da partitura de gestos, ações e movimentos que definem a dramaturgia.

As peças não têm apenas uma situação principal, um conflito central, nem personagem protagonista. Predomina a definição de um assunto, o tema e em torno dele giram situações, ações e imagens. Mas também ocorre a justaposição de cenas sem relação aparente, imagens e ações desconexas.

A ruptura com a narrativa linear, a narrativa com princípio, meio e fim, na qual se conta uma história, onde cada acontecimento é a sequiência da ação anterior é substituída por uma proposta de narrativa desconstruída, desordenada. Situações que ora apresentam uma seqüência, mas em seguida são abandonadas, interrompidas por uma imagem em movimento que possibilita ao espectador imaginar, refletir ou somente desfrutar da beleza da imagem, contrastando com situações antes mostradas. Dentre os diversos trabalhos que exemplificam tal tendência destacam-se A Infecção Sentimental Contra-Ataca (1985) e Babel Bum (1994), dirigidos por Osvaldo Gabrieli, com o Grupo XPTO; Submundo (2002), do Grupo Sobrevento, sob a direção de Luiz André Cherubini; e Dicotomias - fragmentos Esquizofrê (2003), do Grupo O Casulo BonecObjeto, com direção de Ana Maria Amaral.

c) a intertextualidade - Outro percurso que caracteriza uma nova forma de criação do espetáculo pode ser definida pela intertextualidade. Trata-se de um procedimento que busca, em fontes existentes, os dados e elementos que fazem parte do texto ou da cena. Do ponto de vista da dramaturgia, consiste em recolher trechos de textos de diversos autores, nem sempre textos dramáticos, e que postos numa disposição dão um novo sentido, às vezes, diferente da intenção com que foram originalmente 
criados. A unidade temática é formatada pelo dramaturgo ou diretor que, ao utilizar material já existente, assume a posição de "coletor", e com freqüência usa o recurso da colagem e negligencia o encadeamento lógico de idéias.

Na perspectiva do texto, intertextualidade é compreendida como: "Todo texto se constrói como um mosaico de citações, todo texto é absorção e transformação de um outro texto" (KRISTEVA Apud RÖHL, 1997, p.29). Mas esse procedimento também se caracteriza pela interface com outras linguagens artísticas como a dança, artes plásticas, imagens gravadas/filmadas produzindo surpresas, dúvidas e certo distanciamento no público. Para Cohen, que prefere a expressão "intertextualidades", elas acontecem "entre a palavra, as materialidades e as imagens, nas formas antes que nos sentidos, nas poéticas desejantes que dão vazão às corporalidades, às expressões do sujeito nas paisagens do inconsciente e em suas mitologias primordiais" (COHEN, 2001, p.106). São espetáculos que abandonam o gueto do boneco (sobretudo o do tipo antropomorfo) e utilizam formas, objetos, imagens, distanciando-se dos registros que a tornaram conhecida do grande público. Em relação ao uso do objeto/boneco na cena contemporânea Costa destaca que:

\footnotetext{
O teatro pode ser experenciado como a arte do espaço e do tempo, deixando (entre)ver, simultaneamente, os corpos e os objetos no espaço físico palpável e no espaço imaginário. Neste aspecto, a atuação (animação/manipulação) com objetos torna-se um território amplo de experimentações, no qual o espectador localiza o objeto não apenas no cosmo fictício da cena, mas também na situação "real" em que se dá o evento teatral (COSTA, 2008, p.22).
}

Nesta modalidade de trabalho, é interessante observar que a identificação do público com o espetáculo também se dá na medida em que reconhece/lembra de trechos dos textos de autores conhecidos, presentes na dramaturgia. Isso denota a importância de referências na criação dessa modalidade de trabalho.

Vale ressaltar que tais facetas que caracterizam alguns processos de criação de espetáculos são cambiantes, estão em permanente movimento e, não raro, se interpenetram, podendo estar às vezes mais, às vezes menos visíveis. Dentre os espetáculos criados nessa perspectiva destacam-se duas montagens da Cia. Pia Fraus, de São Paulo: Flor de Obsessão (1996), baseada em textos de Nelson Rodrigues com direção de Francisco Medeiros, e 100 Shakespeare (2006), dirigido por Beto Andretta e Wanderley Piras. 
O modo de criação de espetáculos de teatro de animação hoje se transformou e as suas criações representam diversas tendências. Já não é possível visualizar uma poética predominante. $\mathrm{O}$ trabalho dos grupos se caracteriza por trajetórias distintas no seu modo de criação podendo ser identificadas ora com o teatro de bonecos mais tradicional, aquele do final do século XVIII, ora com criações que se aproximam bastante das idéias de heterogeneidade que caracterizam encenações mais contemporâneas. $\mathrm{O}$ que resulta num teatro híbrido e miscigenado que combina e se apropria de outras linguagens criando novos modos de expressão. Ao mesmo tempo, na visão do diretor teatral francês Dominique Houdart as experimentações de muitos grupos retomam as origens mais caras dessa arte: "O teatro de figura [animação] é o teatro de parte alguma, o teatro da utopia, longe de qualquer realismo, retorno às fontes profundas da teatralidade" (HOUDART, 2007, p.31). Tais trajetórias apontam para a existência de micro-poéticas resultantes de experimentações e criações trilhadas durante anos de trabalho. Muitos grupos sistematizam um trabalho processual, agregam variadas aptidões e saberes que resultam em espetáculos com características definidoras de sua identidade. Enquanto alguns trabalhos se inspiram em técnicas e princípios centenários, outros buscam a comunicação com o público utilizando recursos mais atuais. Importante é constatar que, mesmo com as visíveis transformações apontadas no modo de criar espetáculos, sob o vasto campo do teatro de animação há espaço para todas as tendências, sem hierarquia quanto à importância ou valor para o teatro brasileiro.

\section{REFERÊNCIAS:}

BARBA, Eugenio; SARAVESE, Nicola. A Arte Secreta do Ator: dicionário de antropologia teatral. Campinas: Hucitec, 1995.

BELTRAME, Valmor. Reflexões sobre o teatro de animação no Brasil In: Vida de Boneco. Curitiba : ImagemSul, 2006.

BELTRAME, Valmor. Teatro de Formas Animadas Contemporâneo: hibridismo, miscigenação e heterogeneidade. In: Móin-Móin Revista de Estudos sobre Teatro de Formas Animadas N.4. Jaraguá do Sul: SCAR/UDESC, ano3, v4, 2007.

BORBA FILHO, Hermilo. Fisionomia e Espírito do Mamulengo. Rio de Janeiro: INACEN, 1987.

CANCLINI, Nestor Garcia. Culturas Hibridas. São Paulo: Edusp, 2003. 
COHEN, Renato. Teatro brasileiro contemporâneo: matrizes teóricas e interculturalidade. In: Sala Preta - Revista de Artes Cênicas - ECA/USP. São Paulo, N.1, 2001.

COSTA, Felisberto Sabino da. Algumas palavras sobre a arte da manipulação (ou da animação) ou conforme os desideratos de cada qual. In BELTRAME, Valmor (Org.) Teatro de Bonecos: distintos olhares sobre teoria e prática. Florianópolis, UDESC, 2008.

DUBATTI, Jorge. Títeres em la Argentina: câmbios conceptuales em la posdictadura. In Móin-Móin Revista de Estudos sobre Teatro de Formas Animadas N.4. Jaraguá do Sul: SCAR/UDESC, ano3, v4, 2007.

HOUDART, Dominique:Manifesto por um teatro de marionete e de figura. In MóinMóin Revista de Estudos sobre Teatro de Formas Animadas N.4. Jaraguá do Sul: SCAR/UDESC, ano3, v4, 2007.

RÖHL, Ruth. O Teatro de Heiner Müller. São Paulo. Perspectiva, 1997.

SANTOS, Fernando Augusto Gonçalves. Mamulengo: o teatro de bonecos popular do Brasil. In: Móin-Móin - Revista de Estudos sobre Teatro de Formas Animadas N.3. Jaraguá do Sul: SCAR/UDESC, ano3, v3, 2007. 